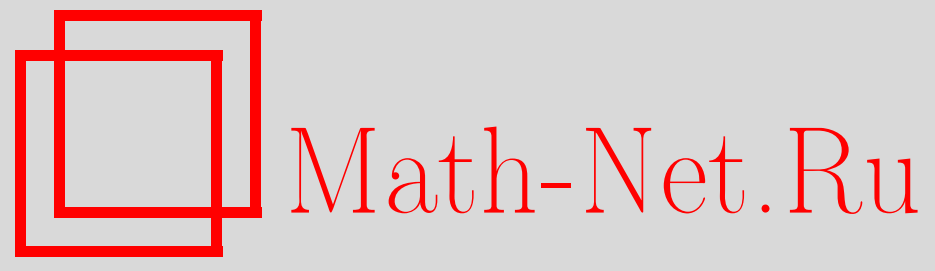

D. V. Ivanov, Идентификация линейных динамических систем дробного порядка с ошибками в переменных на основе расширенной системы уравнений, Вестн. Сам. гос. техн. ун-та. Сер. Физ.мат. науки, 2021, номер 3, 508-518

DOI: https://doi.org/10.14498/vsgtu1854

Использование Общероссийского математического портала MathNet.Ru подразумевает, что вы прочитали и согласны с пользовательским соглашением

http: //www . mathnet.ru/rus/agreement

Параметры загрузки:

IP : 35.173 .137 .237

26 апреля 2023 г., 17:35:22

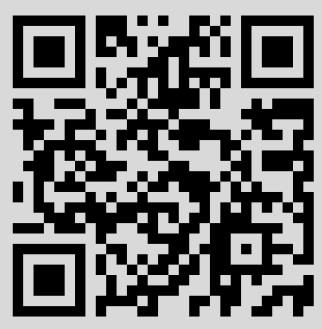


MSC: 93E12, 15A29

\title{
Identification of linear dynamic systems of fractional order with errors in variables based on an augmented system of equations
}

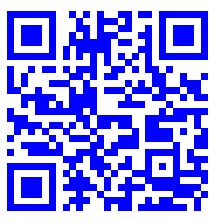

(C) D. V. Ivanov

Samara State Transport University,

2 V, Svobody st., Samara, 443066, Russian Federation.

\begin{abstract}
Equations with derivatives and fractional order differences are widely used to describe various processes and phenomena. Currently, methods of identification of systems described by equations with fractional order differences are actively developing. The paper is devoted to the identification of discrete dynamical systems described by equations with fractional order differences with errors in variables. The problems of identifying systems with errors in variables are often ill-conditioned. The paper proposes an algorithm that uses the representation of a normal biased system as an augmented equivalent system. This representation allows to reduce the number of conditionality of the problem to be solved. Test examples have shown that the proposed algorithm has a higher accuracy than the algorithms based on the decomposition of Cholesky and the minimization of the generalized Rayleigh quotient.
\end{abstract}

Keywords: fractional difference, total least square, errors-in-variables, illconditioning.

Received: $20^{\text {th }}$ March, $2021 /$ Revised: $24^{\text {th }}$ June, $2021 /$

Accepted: $28^{\text {th }}$ June, $2021 /$ First online: $27^{\text {th }}$ September, 2021

Introduction. Equations with fractional-order derivatives and differences are widely used to describe various processes and phenomena. Models based on equations with fractional-order derivatives and differences find wide application in hydrology, economics, and forecasts of network data usage [1-3]. Besides, the branch of management theory dealing with the synthesis of fractional order regulators is developing actively. Mechanics was one of the first fields to use equations with fractional order derivatives. A large amount of research deals with viscoelasticity models [4-7].

\section{Research Article}

( ) (1) The content is published under the terms of the Creative Commons Attribution 4.0 International License (http://creativecommons.org/licenses/by/4.0/)

Please cite this article in press as:

Iv a n o v D. V. Identification of linear dynamic systems of fractional order with errors in variables based on an augmented system of equations, Vestn. Samar. Gos. Tekhn. Univ., Ser. Fiz.-Mat. Nauki [J. Samara State Tech. Univ., Ser. Phys. Math. Sci.], 2021, vol. 25, no. 3, pp. 508-518. https://doi.org/10.14498/vsgtu1854.

\section{Author's Details:}

Dmitriy V. Ivanov (1) https://orcid.org/0000-0002-5021-5259

Cand. Phys. \& Math. Sci.; Associate Professor; Dept. of Mechatronics, Automation, and Transport Control; e-mail: dvi85@list.ru 
Generally, the creep and relaxation processes for actual nonuniform media are nonlinear both in space and in time. As a result, using fractional-order derivatives in the state equations for viscoelastic media makes it possible to display and factor in the nonuniform structures of viscous and elastic elements and the nonuniformity of mechanical processes in time.

Because equations with fractional order derivatives and differences are actively being developed and used for forecast and modeling problems, methods for identifying systems described by fractional-order equations and differences are actively being developed as well. Noise-free identification methods have been treated for ordinary differential equations with fractional order derivatives [8] and for partial differential equations with fractional order derivatives [9].

Most of the research in the field deals with parameter identification of fractional order differential equations by using the error in an equation or in an output signal. References $[10,11]$ describe time domain identification methods based on the least-square technique. Reference [12] presents an overview of different methods for identifying systems with fractional-order derivatives.

It is noteworthy that a fairly large amount of research addresses the problem of identifying viscoelasticity models [13-16]. That research deals with identifying fractional order models such as a generalized model with a fixed number of parameters. Results generalization for the case of an arbitrary number of parameters is a nontrivial operation. Most of the methods we considered disregard the presence of measurement errors.

The problem of identifying systems that have errors in input and output signals is much more complicated. Reference [17] gives an overview of the contemporary state of this problem. A relatively small amount of research attention has been given to identifying systems with fractional order derivatives and differences in the presence of those errors. Methods based on higher statistics have been proposed in $[18,19]$; methods based on minimizing the generalized Rayleigh ratio have been treated in [20] (for white noise) and in [22] (for fractional white noise).

This paper proposes generalizing the identification algorithm [23] for equations with fractional order differences. The proposed algorithm makes it possible to achieve more accurate estimates than those in [20] for ill-conditioned systems.

1. Problem statement. Fractional-order systems can be represented by the fractional difference equation given by

$$
z_{i}=\sum_{m=1}^{r} b_{0}^{(m)} \Delta^{\alpha_{m}} z_{i-1}+\sum_{m=1}^{r_{1}} a_{0}^{(m)} \Delta^{\beta_{m}} x_{i}, \quad y_{i}=z_{i}+\xi_{i}, \quad w_{i}=x_{i}+\zeta_{i},
$$

where $b_{0}^{(m)}, a_{0}^{(m)}$ are coefficients; $0<\alpha_{1} \ldots<\alpha_{r}, 0<\beta_{1} \ldots<\beta_{r_{1}}$;

$$
\Delta^{\alpha_{m}} z_{i}=\sum_{j=0}^{i}(-1)^{j}\left(\begin{array}{c}
\alpha_{m} \\
j
\end{array}\right) z_{i-j}, \quad \Delta^{\beta_{m}} x_{i}=\sum_{j=0}^{i}(-1)^{j}\left(\begin{array}{c}
\beta_{m} \\
j
\end{array}\right) x_{i-j}
$$

are fractional differences [1];

$$
\left(\begin{array}{c}
\alpha_{m} \\
j
\end{array}\right)=\frac{\Gamma\left(\alpha_{m}+1\right)}{\Gamma(j+1) \Gamma\left(\alpha_{m}-j+1\right)}, \quad\left(\begin{array}{c}
\beta_{m} \\
j
\end{array}\right)=\frac{\Gamma\left(\beta_{m}+1\right)}{\Gamma(j+1) \Gamma\left(\beta_{m}-j+1\right)}
$$


are the generalized binomial coefficients; the Euler's function $\Gamma$ is defined as

$$
\Gamma(\alpha)=\int_{0}^{\infty} e^{-t} t^{\alpha-1} d t .
$$

Autoregressions with fractional differences are widely used in the analysis of time series with long memory [24, 25]. In [26], a discrete Kalman filter with fractional differences is proposed. Equations with fractional order differences of the form (1) are also used to approximate differential equations with GrunfeldLetnikov derivatives; the identification of such systems is considered in [27]. Modeling of various physical processes based on equations with fractional-order differences is considered in [28, 29].

The following assumptions are introduced:

1. The dynamic system (1) is asymptotically stable. Results on the asymptotic stability of discrete-time fractional difference systems in [30, 31].

If system (1) is unstable, then the output signal increases indefinitely. This leads to overflow of the bit grid. Therefore, obtaining a solution for unstable systems has additional computational difficulties that are not considered in this paper. There is also no theoretical proof of strong consistency for discrete fractional systems with errors in variables.

2. Noises $\left\{\xi_{i}\right\}$ and $\left\{\zeta_{i}\right\}$ are statistically independent sequences with $\mathrm{E}\left\{\xi_{i}\right\}=0$, $\mathrm{E}\left\{\zeta_{i}\right\}=0, \mathrm{E}\left\{\xi_{i}^{2}\right\}=\sigma_{\xi}^{2}<\infty, \mathrm{E}\left\{\zeta_{i}^{2}\right\}=\sigma_{\zeta}^{2}<\infty$ a.s., where $\mathrm{E}$ is the expectation operator.

3. The sequences $\left\{\xi_{i}\right\}$ and $\left\{\zeta_{i}\right\}$ are mutually uncorrelated and uncorrelated with sequences $\left\{z_{i}\right\},\left\{x_{i}\right\}$.

4. The noise-free input sequence $\left\{x_{i}\right\}$ is persistently exciting of sufficiently high order.

5. Noise ratio $\gamma=\sigma_{\xi}^{2} / \sigma_{\zeta}^{2}$ is known.

It is required to estimate the unknown coefficients linear fractional order dynamical system, described by the equation (1) in observable sequences $\left\{y_{i}\right\},\left\{w_{i}\right\}$.

2. Criteria for parameter estimation. In [20] the following criterion was proposed for estimating the parameters of a system described by equations

$$
\min _{\theta \in \tilde{\mathrm{B}}} \sum_{i=1}^{N} \frac{\left(y_{i}-\varphi_{i}^{\top} \theta\right)^{2}}{1+b^{\top} H_{\xi} b+\gamma a^{\top} H_{\zeta} a},
$$

where

$$
\begin{gathered}
H_{\xi}^{(m k)}=\lim _{N \rightarrow \infty} \frac{1}{N}\left(\sum_{j=0}^{N-1}\left(\begin{array}{c}
\alpha_{m} \\
j
\end{array}\right)\left(\begin{array}{c}
\alpha_{k} \\
j
\end{array}\right) \cdot \frac{N-j}{N}\right), \quad m=\overline{1, r}, \quad k=\overline{1, r} \\
H_{\zeta}^{(m k)}=\lim _{N \rightarrow \infty} \frac{1}{N}\left(\sum_{j=0}^{N-1}\left(\begin{array}{c}
\beta_{m} \\
j
\end{array}\right)\left(\begin{array}{c}
\beta_{k} \\
j
\end{array}\right) \cdot \frac{N-j}{N}\right), \quad m=\overline{1, r_{1}}, \quad k=\overline{1, r_{1}} ; \\
\theta=\left(b^{(1)}, \ldots, b^{(r)} \mid a^{(1)}, \ldots, a^{\left(r_{1}\right)}\right)^{\top}, \\
\varphi_{i}=\left(\Delta^{\alpha_{1}} z_{i-j-1}, \ldots, \Delta^{\alpha_{r}} z_{i-j-1} \mid \Delta^{\beta_{1}} x_{i-j}, \ldots, \Delta^{\beta_{r_{1}}} x_{i-j}\right)^{\top} .
\end{gathered}
$$


We transform the criterion (2) in the following form

$$
\begin{gathered}
\min _{\theta \in \tilde{\mathrm{B}}} \frac{\|d-C \theta\|_{2}^{2}}{1+\theta^{\top} H_{\xi \zeta}^{\prime} \theta}, \\
H_{\xi \zeta}=\left(\begin{array}{c|c}
H_{\xi} & 0 \\
\hline 0 & \gamma H_{\zeta}
\end{array}\right), \quad d=\left(y_{1}, \ldots, y_{N}\right)^{\top}, \quad C=\left(\varphi_{1}^{\top}, \ldots, \quad \varphi_{N}^{\top}\right)^{\top} .
\end{gathered}
$$

Theorem. Suppose that the dynamical system is described by equation (1) with initial zero conditions and that assumptions 1-5 are satisfied. Then the estimate for coefficients $\hat{\theta}(N)$ determined by expression (2) exists, is unique, and converges to the true value of the coefficients with a probability of 1 - that is,

$$
\hat{\theta}(N) \underset{\mathrm{N} \rightarrow \infty}{\stackrel{a . s}{\rightarrow}} \theta_{0}
$$

The proof of the theorem is similar to the proof given in [21].

The modeling results show that the accuracy of the algorithm proposed in [20] is not satisfactory for ill-conditioned systems.

One of the approaches used to write numerically stable algorithms is transforming problem (3) into a problem of total least squares for which stable numerical implementations exist.

Let us transform problem (3) into a problem of total least squares. According to condition 4 , the matrix $H_{\xi \zeta}$ is positively definite, and so we will express it as the Cholesky decomposition

$$
H_{\xi \zeta}=U_{\xi \zeta}^{\top} U_{\xi \zeta}
$$

Let us introduce a new variable

$$
\vartheta=U_{\xi \zeta} \theta
$$

Then criterion (3) can be written as

$$
\min _{\vartheta \in \mathrm{B}^{\prime}} \frac{\left\|d-C U_{\xi \zeta}^{-1} \vartheta\right\|_{2}^{2}}{1+\vartheta^{\top} \vartheta} .
$$

3. Numerical methods for the problem of total least squares. There are several approaches to minimizing (4). One of them is based on the fact that solving problem (4) requires calculating the minimal singular value for the extended matrix $\left(C U_{\xi \zeta}^{-1}, d\right)$ and the right singular vector corresponding to that value.

The problem of finding the singular vector is a nonlinear vector problem. Solving that problem numerically involves significant difficulties [32] related to convergence issues, high computational complexity, and the stability of search algorithms.

Another approach is based on solving a biased normal system. Reference [33] shows that given the satisfaction of the condition

$$
\lambda=\lambda_{\min }\left(C U_{\xi \zeta}^{-1}, d\right)<\lambda_{\min }\left(C U_{\xi \zeta}^{-1}\right)
$$


solution to problem (4) is obtainable from the system ofequations

$$
\left(\left(C U_{\xi \zeta}^{-1}\right)^{\top} C U_{\xi \zeta}^{-1}-\lambda^{2} I\right) \vartheta=\left(C U_{\xi \zeta}^{-1}\right)^{\top} d
$$

When system (6) is solved, only the scalar problem of finding the minimal singular value $\lambda_{\min }\left(C U_{\xi \zeta}^{-1}, d\right)$ is remained nonlinear. This problem is always wellconditioned [32]. The vector problem is in turn linear. But system (6) is often ill-conditioned. The condition number of the shifted normal matrix is obtainable from the expression

$$
\operatorname{cond}_{2}\left(\tilde{C}^{\top} \tilde{C}\right) \triangleq \operatorname{cond}_{2}\left(\left(C U_{\xi \zeta}^{-1}\right)^{\top} C U_{\xi \zeta}^{-1}-\lambda^{2} I\right)=\frac{\lambda_{\max }^{2}\left(C U_{\xi \zeta}^{-1}\right)-\lambda^{2}}{\lambda_{\min }^{2}\left(C U_{\xi \zeta}^{-1}\right)-\lambda^{2}}
$$

There are two reasons why (5) is ill-conditioned: the multiplication $\left(C U_{\xi \zeta}^{-1}\right)^{\top} C U_{\xi \zeta}^{-1}$ and the possible proximity of numbers $\lambda_{\min }^{2}\left(C U_{\xi \zeta}^{-1}\right)$ and $\lambda^{2}$.

The use of the Cholesky method can make the solution more stable. As this method applies to systems of linear equations with symmetrical positively definite matrices, it can also be used for the biased normal system (6). But the Cholesky method suffers from a severe drawback: if the matrix is ill-conditioned, the method yields a solution with unacceptable error.

Reference [23] proposes using an augmented system of equations that is equivalent to the biased normal system:

$$
A \bar{\vartheta}=\bar{d}
$$

or

$$
\left(\begin{array}{c|c|c}
I & 0 & C U_{\xi \zeta}^{-1} \\
\hline 0 & I & j \lambda I \\
\hline\left(C U_{\xi \zeta}^{-1}\right)^{\top} & j \lambda I & 0
\end{array}\right)\left(\begin{array}{c}
r \\
\hline r_{\xi \zeta} \\
\hline \hat{\vartheta}
\end{array}\right)=\left(\begin{array}{c}
d \\
\hline 0 \\
\hline 0
\end{array}\right) .
$$

The expression for the condition number of matrix $A$ is written as

$$
\operatorname{cond}_{2}(A)=\frac{\sqrt{1+\mu_{\max }+\lambda^{2}}}{\sqrt{1+\mu_{\min }+\lambda^{2}}}\left|\frac{\cos \left(\frac{1}{3} \arccos \left(\frac{3 \sqrt{3}}{2} \frac{\mu_{\max }-\lambda^{2}}{\left(1+\mu_{\max }+\lambda^{2}\right)^{3 / 2}}\right)\right)}{\cos \left(\frac{\pi}{3}+\frac{1}{3} \arccos \left(\frac{3 \sqrt{3}}{2} \frac{\mu_{\min }-\lambda^{2}}{\left(1+\mu_{\min }+\lambda^{2}\right)^{3 / 2}}\right)\right)}\right|
$$

where $\mu_{\max }$ and $\mu_{\min }$ are the maximal and minimal eigenvalues of the matrix $C U_{\xi \zeta}^{-1}\left(C U_{\xi \zeta}^{-1}\right)^{\top}$.

An analysis of expression (7) shows that using the augmented system of equations does not always reduce the condition number of the matrix compared to the biased normal system (6).

Let us consider the system

$$
\left(\begin{array}{c|c|c}
I & 0 & k C U_{\xi \zeta}^{-1} \\
\hline 0 & I & j k \lambda I \\
\hline\left(k C U_{\xi \zeta}^{-1}\right)^{\top} & j k \lambda I & 0
\end{array}\right)\left(\begin{array}{c}
k r \\
\hline \frac{k r_{\xi \zeta}}{\hat{\vartheta}}
\end{array}\right)=\left(\begin{array}{c}
\frac{k d}{0} \\
\hline 0
\end{array}\right)
$$


where $k$ is an arbitrary positive variable multiplier.

The condition number of matrix $A(k)$ is written as

$\operatorname{cond}_{2}(A(k))=\frac{\sqrt{1+k^{2} \mu_{\max }+k^{2} \lambda^{2}}}{\sqrt{1+k^{2} \mu_{\min }+k^{2} \lambda^{2}}}\left|\frac{\cos \left(\frac{1}{3} \arccos \left(\frac{3 \sqrt{3}}{2} \frac{k^{2}\left(\mu_{\max }-\lambda^{2}\right)}{\left(1+k^{2} \mu_{\max }+k^{2} \lambda^{2}\right)^{3 / 2}}\right)\right)}{\cos \left(\frac{\pi}{3}+\frac{1}{3} \arccos \left(\frac{3 \sqrt{3}}{2} \frac{k^{2}\left(\mu_{\min }-\lambda^{2}\right)}{\left(1+k^{2} \mu_{\min }+k^{2} \lambda^{2}\right)^{3 / 2}}\right)\right)}\right|$.

The problem of finding the minimal condition number can be considered as the problem of selecting the optimal multiplier $k$ :

$$
\inf _{k>0} \operatorname{cond}_{2}(A(k)) \text {. }
$$

Problem (9) does not have an analytical solution but is solvable with numerical methods. In practice, an estimate of $k_{\text {opt }}$ can be given by

$$
\hat{k}_{\mathrm{opt}}=\frac{\lambda_{\max }\left(C U_{\xi \zeta}^{-1}\right)+\lambda}{\lambda_{\min }\left(C U_{\xi \zeta}^{-1}\right)+\lambda} \sqrt{\frac{2}{\lambda_{\max }^{2}\left(C U_{\xi \zeta}^{-1}\right)+\lambda^{2}}}
$$

The augmented system of equations (8) is solvable with the standard methods for solving equation systems, such as LU decomposition.

The equation $\hat{\vartheta}=U_{\xi \zeta} \hat{\theta}$ can yield an estimate for the parameter vector $\hat{\theta}$ :

$$
\hat{\theta}=U_{\xi \zeta}^{-1} \hat{\vartheta}
$$

Algorithm.

STEP 1. Decompose

$$
H_{\xi \zeta}^{\prime}=U_{\xi \zeta}^{\top} U_{\xi \zeta}
$$

SteP 2. Find the minimal singular value for the matrix $\left(C U_{\xi \zeta}^{-1}, d\right)$.

Step 3. Calculate the multiplier with (9) or (10).

SteP 4. Solve equation system (8) with the Gauss method or with algorithm [23].

STEP 5. Find an estimate of the coefficient vector by $\hat{\theta}=U_{\xi \zeta}^{-1} \hat{\vartheta}$.

4. Test Examples. The proposed algorithm has been compared with the algorithm based on Cholesky decomposition and the algorithm based on the generalized Rayleigh quotient (GRQ) in [20].

Test cases were compared by the following characteristics:

- the normalized root mean square error (NRMSE) of parameter estimation defined as

$$
\delta \theta=\sqrt{\left\|\hat{\theta}-\theta_{0}\right\|^{2} /\left\|\theta_{0}\right\|^{2}} \cdot 100 \%
$$

- and normalized root mean square error of modelling defined as

$$
\delta z=\sqrt{\|\hat{z}-z\|^{2} /\|z\|^{2}} \cdot 100 \%
$$

The number of data points $N$ in each simulation was 200 . 
EXAMPLE 1. A dynamic system is described by the equation

$$
z_{i}=0.5 \Delta^{0.2} z_{i-1}+0.3 \Delta^{0.1} z_{i-1}+\Delta^{0.2} x_{i}^{(1)}+0.9 \Delta^{0.15} x_{i}^{(1)} .
$$

Noise standard deviation ratio

$$
\sigma_{\xi} / \sigma_{z}=10^{-3}, \quad \sigma_{\zeta} / \sigma_{x}=0.2
$$

The results are presented in tables 1,2 .

Table 1

Normalized root mean square error for dynamic system (11)

\begin{tabular}{c|c|c}
\hline $\operatorname{cond}_{2}\left(\tilde{C}^{\top} \tilde{C}\right)$ & $\operatorname{cond}_{2}(A)$ & $\operatorname{cond}_{2}(A(k))$ \\
\hline $3.143 \cdot 10^{5}$ & $9.55 \cdot 10^{3}$ & $1.73 \cdot 10^{3}$ \\
\hline
\end{tabular}

Table 2

Values of condition numbers for a dynamic system (11)

\begin{tabular}{c|c|c|c}
\hline NRMSE & GRQ & Cholesky decomposition & Proposed algorithm \\
\hline$\delta \theta, \%$ & 4.55 & 4.55 & 4.55 \\
$\delta z, \%$ & 1.03 & 1.03 & 1.03 \\
\hline
\end{tabular}

EXAmple 2. A dynamic system is described by the equation

$$
z_{i}=0.5 \Delta^{0.2} z_{i-1}+0.3 \Delta^{0.19} z_{i-1}+\Delta^{0.2} x_{i}^{(1)}+0.9 \Delta^{0.15} x_{i}^{(1)} .
$$

Noise standard deviation ratio

$$
\sigma_{\xi} / \sigma_{z}=10^{-10}, \quad \sigma_{\zeta} / \sigma_{x}=0.2
$$

The results are presented in tables 3,4 .

Table 3

Normalized root mean square error for dynamic system (12)

\begin{tabular}{c|c|c}
\hline $\operatorname{cond}_{2}\left(\tilde{C}^{\top} \tilde{C}\right)$ & $\operatorname{cond}_{2}(A)$ & $\operatorname{cond}_{2}(A(k))$ \\
\hline $1.03 \cdot 10^{19}$ & $1.07 \cdot 10^{15}$ & $4.14 \cdot 10^{9}$ \\
\hline
\end{tabular}

Table 4

Values of condition numbers for a dynamic system (12)

\begin{tabular}{c||c|c|c}
\hline NRMSE & GRQ & Cholesky decomposition & Proposed algorithm \\
\hline$\delta \theta, \%$ & 1126.45 & 3.03 & 3.03 \\
$\delta z, \%$ & 241.03 & 0.67 & 0.67 \\
\hline
\end{tabular}

EXAmple 3. A dynamic system is described by the equation

$$
z_{i}=0.5 \Delta^{0.2} z_{i-1}+0.3 \Delta^{0.199} z_{i-1}+\Delta^{0.2} x_{i}^{(1)}+0.9 \Delta^{0.15} x_{i}^{(1)} .
$$

Noise standard deviation ratio

$$
\sigma_{\xi} / \sigma_{z}=10^{-14}, \quad \sigma_{\zeta} / \sigma_{x}=0.2 .
$$

The results are presented in tables 5, 6 . 
Table 5

Normalized root mean square error for dynamic system (13)

\begin{tabular}{c|c|c}
\hline $\operatorname{cond}_{2}\left(\tilde{C}^{\top} \tilde{C}\right)$ & $\operatorname{cond}_{2}(A)$ & $\operatorname{cond}_{2}(A(k))$ \\
\hline $9.46 \cdot 10^{33}$ & $5.01 \cdot 10^{15}$ & $5.86 \cdot 10^{9}$ \\
\hline
\end{tabular}

Table 6

Values of condition numbers for a dynamic system (13)

\begin{tabular}{c||c|c|c}
\hline NRMSE & GRQ & Cholesky decomposition & Proposed algorithm \\
\hline$\delta \theta, \%$ & 6528.96 & 235.58 & 0.14 \\
$\delta z, \%$ & 162.93 & 0.77 & 0.53 \\
\hline
\end{tabular}

Conclusion. The examples show that with relatively small condition numbers, all three algorithms exhibit identical results. The least stable is the algorithm based on minimizing the generalized Rayleigh ratio, while the proposed algorithm is the most stable.

Competing interests. I have no competing interests.

Author's Responsibilities. I take full responsibility for submit the final manuscript to print. I approved the final version of the manuscript.

Acknowledgments. The author is also grateful to the anonymous referee for his careful reading of the manuscript and valuable comments and suggestions.

\section{References}

1. Podlubny I. Fractional differential equations. An introduction to fractional derivatives, fractional differential equations, to methods of their solution and some of their applications, Mathematics in Science and Engineering, vol. 198. San Diego, Academic Press, 1999, xxiv +340 pp. https://doi.org/10.1016/s0076-5392(99)x8001-5.

2. Kilbas A. A., Srivastava H. M., Trujillo J. J. Theory and Applications of Fractional Differential Equations, North-Holland Mathematics Studies, vol. 204. Amsterdam, Elsevier, 2006, $\mathrm{xx}+523$ pp. https://doi.org/10.1016/s0304-0208(06)x8001-5.

3. Uchaikin V. V. Heredity and nonlocality, In: Fractional Derivatives for Physicists and Engineers. Background and Theory, vol. 1, Nonlinear Physical Science. Berlin, Springer, 2013, pp. 3-58. https://doi.org/10.1007/978-3-642-33911-0_1.

4. Rabotnov Yu. N. Elements of Hereditary Solid Mechanics, Mir Publ., 1980, 388 pp.

5. Slonimsky G. L. On the laws of deformation of real materials. I. The theories of Maxwell and Boltzmann, Acta Physicochim. URSS, 1940, vol.12, pp. 99-128.

6. Mainardi F. Fractional Calculus and Waves in Linear Viscoelasticity. An Introduction to Mathematical Models. Hackensack, NJ, World Scientific, 2010, xx+347 pp. https://doi. org/10.1142/p614.

7. Koeller R. C. Applications of fractional calculus to the theory of viscoelasticity, J. Appl. Mech., 1984, vol.51, no.2, pp. 299-307. https://doi.org/10.1115/1.3167616.

8. Boikov I. V., Krivulin N. P. Parametric identification of hereditary systems with distributed parameters, University Proceedings. Volga Region. Engineering Sciences, 2013, vol. 26, no. 2, pp. 120-129 (In Russian).

9. Boykov I. V., Krivulin N. P. Recovery of the parameters of linear systems described by differential equations with variable coefficients, Meas. Tech., 2013, vol.56, no. 4, pp. 359356. https://doi.org/10.1007/s11018-013-0210-5.

10. Cois O., Oustaloup A., Battaglia E., Battaglia J.-L. Non integer model from modal decomposition for time domain system identification, IFAC Proc. Vol., 2000, vol. 33, no. 15, pp. 989-994. https://doi.org/10.1016/S1474-6670(17)39882-8. 
11. Cois O., Oustaloup A., Poinot T., Battaglia J.-L. Fractional state variable filter for system identification by fractional model, In: 2001 European Control Conference (ECC) (4-7 Sept. 2001, Porto, Portugal), 2001, pp. 2481-2486. https://doi.org/10.23919/ECC. 2001.7076300 .

12. Malti R., Aoun M., Sabatier J., Oustaloup A. Tutorial on system identification using fractional differentiation models, IFAC Proc. Vol., 2006, vol.39, no.1, pp. 606-611. https:// doi.org/10.3182/20060329-3-AU-2901.00093.

13. Ogorodnikov E. N., Radchenko V. P., Ungarova L. G. Mathematical modeling of hereditary elastically deformable body on the basis of structural models and fractional integrodifferentiation Riemann-Liouville apparatus, Vestn. Samar. Gos. Tekhn. Univ., Ser. Fiz.Mat. Nauki [J. Samara State Tech. Univ., Ser. Phys. Math. Sci.], 2016, vol. 20, no. 1, pp. 167194 (In Russian). https://doi.org/10.14498/vsgtu1456.

14. Ungarova L. G. The use of linear fractional analogues of rheological models in the problem of approximating the experimental data on the stretch polyvinylchloride elastron, Vestn. Samar. Gos. Tekhn. Univ., Ser. Fiz.-Mat. Nauki [J. Samara State Tech. Univ., Ser. Phys. Math. Sci.], 2016, vol.20, no.4, pp. 691-706 (In Russian). https://doi.org/10.14498/ vsgtu1523.

15. Lewandowski R., Chorążyczewski B. Identification of the parameters of the Kelvin-Voigt and the Maxwell fractional models, used to modeling of viscoelastic dampers, Comp. Struct., 2009, vol. 88, no.1-2, pp. 1-17. https://doi.org/10.1016/j.compstruc.2009.09.001.

16. Shabani R., Jahani K., Di Paola M., Sadeghi M. N. Frequency domain identification of the fractional Kelvin-Voigt's parameters for viscoelastic materials, Mech. Mater., 2019, vol. 137, 103099. https://doi.org/10.1016/j.mechmat.2019.103099.

17. Söderström T. Errors-in-Variables Methods in System Identification, Communications and Control Engineering. Cham, Switzerland, Springer, 2018, xxvii+485 pp. https://doi.org/ 10.1007/978-3-319-75001-9.

18. Chetoui M., Malti R., Thomassin M., Aoun M., Najar S., Oustaloup A., Abdelkrim M.N. EIV methods for system identification with fractional models, IFAC Proceedings Volumes, 2012, vol.45, no.16, pp. 1641-1646. https://doi.org/10.3182/20120711-3-BE-2027. 00270.

19. Chetoui M., Thomassin M., Malti R., Aoun M., Najar S., Abdelkrim M. N., Oustaloup A. New consistent methods for order and coefficient estimation of continuous-time errors-invariables fractional models, Comp. Math. Appl., 2013, vol.66, no. 5, pp. 860-872. https:// doi.org/10.1016/j. camwa.2013.04.028.

20. Ivanov D. V. Identification discrete fractional order linear dynamic systems with errorsin-variables, In: East-West Design and Test Symposium (EWDTS 2013) (27-30 Sept. 2013, Rostov on Don, Russia), 2013, pp. 374-377. https://doi.org/10.1109/EWDTS. 2013. 6673122.

21. Ivanov D. V. Estimation of parameters of linear fractional order ARX systems with noise in the input signal, Tomsk State University Journal of Control and Computer Science, 2014, no. 2(27), pp. 30-38 (In Russian).

22. Ivanov D. V., Ivanov A. V. Identification fractional linear dynamic systems with fractional errors-in-variables, J. Phys.: Conf. Ser., 2017, vol. 803, 012058. https://doi.org/10.1088/ 1742-6596/803/1/012058.

23. Zhdanov A. I., Shamarov P. A. A direct projection method in the problem of complete least squares, Autom. Remote Control, 2000, vol.61, no. 4, pp. 610-620.

24. Granger C. W. J., Joyeux R. An introduction to long-memory time series models and fractional differencing, J. Time Series Anal., 1980, vol.1, no.1, pp. 15-29. https://doi. org/https://doi.org/10.1111/j.1467-9892.1980.tb00297.x.

25. Hosking J. R. M. Fractional differencing, Biometrika, 1981, vol.68, no. 1, pp. 165-176. https://doi.org/10.1093/biomet/68.1.165.

26. Sierociuk D., Dzieliński A. Fractional Kalman filter algorithm for the states parameters and order of fractional system estimation, Int. J. Appl. Math. Comput. Sci., 2006, vol. 16, no. 1, pp. 129-140. 
27. Djouambai A., Voda A., Charef A. Recursive prediction error identification of fractional order models, Commun. Nonlinear Sci. Numer. Simulat., 2012, vol. 17, no. 6, pp. 2517-2524. https://doi.org/10.1016/j.cnsns.2011.08.015.

28. Dzieliński A., Sierociuk D. Some applications of fractional order calculus, Bull. Polish Acad. Sci. Tech. Sci., 2010, vol.58, no.4, pp. 583-592. https://doi.org/10.2478/ v10175-010-0059-6.

29. Ivanov D. V., Ivanov A. V., Sandler I., Chertykovtseva N. V. Identification of the heating model plastic injection molding machines, Zhurnal SVMO, 2017, vol. 19, no. 3, pp. 82-89 (In Russian). https://doi.org/10.15507/2079-6900.19.201703.82-90.

30. Ostalczyk P. Discrete Fractional Calculus. Applications in Control and Image Processing, Series in Computer Vision, vol.4. Hackensack, NJ, World Scientific, 2016, xxxi+361 pp. https://doi.org/10.1142/9833.

31. Mozyrska D., Wyrwas M. Stability of discrete fractional linear systems with positive orders, IFAC-PapersOnLine, 2017, vol.50, no. 1, pp. 8115-8120. https://doi.org/10.1016/ j.ifacol.2017.08.1250.

32. Wilkinson J. H. The Algebraic Eigenvalue Problem, Monographs on Numerical Analysis. Oxford Science Publications. Oxford, Clarendon Press, 1988, xviii +682 pp.

33. Zhdanov A. I. The solution of ill-posed stochastic linear algebraic equations by the maximum likelihood regularization method, U.S.S.R. Comput. Math. Math. Phys., 1988, vol. 28, no. 5, pp. 93-96. https://doi.org/10.1016/0041-5553(88)90014-6. 
Вестн. Сам. гос. техн. ун-та. Сер. Физ.-мат. науки. 2021. Т. 25, № 3. С. $508-518$ ISSN: 2310-7081 (online), 1991-8615 (print)

УДК $\mathbf{5 1 9 . 2 5 4}$

\title{
Идентификация линейных динамических систем дробного порядка с ошибками в переменных на основе расширенной системы уравнений
}

\author{
(С) Д. В. Иванов \\ Самарский государственный университет путей сообщения, \\ Россия, 443066, Самара, ул. Свободы, 2 В.
}

\section{Аннотация}

Уравнения с производными и разностями дробного порядка находят широкое применение для описания различных процессов и явлений. В настоящее время активно развиваются методы идентификации систем, описываемых уравнениями с разностями дробного порядка. Статья посвящена идентификации дискретных динамических систем, описываемых уравнениями с разностями дробного порядка с ошибками в переменных. Задачи идентификации систем с ошибками в переменных часто бывают плохо обусловленными. В статье предложен алгоритм, использующий представление нормальной смещенной системы в виде расширенной эквивалентной системы. Данное представление позволяет уменьшить число обусловленности решаемой задачи. Тестовые примеры показали, что предложенный алгоритм обладает более высокой точностью по сравнению с алгоритмами на основе разложения Холецкого и минимизации обобщенного отношения Релея.

Ключевые слова: разность дробного порядка, полные наименьшие квадраты, ошибки в переменных, плохая обусловленность.

Получение: 20 марта 2021 г. / Исправление: 24 июня 2021 г. / Принятие: 28 июня 2021 г. / Публикация онлайн: 27 сентября 2021 г.

Конкурирующие интересы. Конкурирующих интересов не имею.

Авторская ответственность. Я несу полную ответственность за предоставление окончательной версии рукописи в печать. Окончательная версия рукописи мною одобрена.

Благодарности. Автор благодарит анонимного рецензента за тщательное прочтение статьи и ценные предложения и комментарии.

\section{Научная статья}

(2) (ㄱ) Контент публикуется на условиях лицензии Creative Commons Attribution 4.0 International (https://creativecommons.org/licenses/by/4.0/deed.ru)

\section{Образец для цитирования}

I v a n o v D. V. Identification of linear dynamic systems of fractional order with errors in variables based on an augmented system of equations, Vestn. Samar. Gos. Tekhn. Univ., Ser. Fiz.-Mat. Nauki [J. Samara State Tech. Univ., Ser. Phys. Math. Sci.], 2021, vol. 25, no. 3, pp. 508-518. https://doi.org/10.14498/vsgtu1854.

\section{Сведения об авторе}

Дмитрий Владимирович Иванов (1) https://orcid.org/0000-0002-5021-5259

кандидат физико-математических наук, доцент; доцент; каф. мехатроники, автоматизации, управления на транспорте; e-mail: dvi85@list.ru 